\title{
INSTRUMENTO JURÍDICO UTILIZADO NO COMPARTILHAMENTO DE ESTRUTURAS ENTRE EMPRESA PÚBLICA E SUA SUBSIDIÁRIA INTEGRAL
}

\author{
INSTRUMENTO JURÍDICO UTILIZADO EN LAS ESTRUCTURAS DE \\ INTERCAMBIO ENTRE LA COMPAÑÍA PÚBLICA Y SU SUBSIDIARIA DE \\ PROPIEDAD TOTAL
}

\section{${ }^{1}$ Luciano Monti Favaro}

\section{RESUMO}

Pelo presente artigo pretende-se estudar acerca da subsidiária integral, tal qual definida no artigo 251 da Lei de Sociedade por Ações. Em especial será apresentada suas características, bem como os órgãos sociais que a compreende. Após passa-se a abordar acerca da constituição de subsidiária integral por empresas públicas como forma de descentralizarem a sua atuação no mercado. O questionamento proposto é qual o instrumento jurídico a ser celebrado entre empresa pública e sua subsidiária no compartilhamento de estruturas? Como conclusão verificou-se que o instrumento adequado é um Convênio celebrado nos termos do artigo $116, \S 1^{\circ}$ da Lei 8.666/93.

Palavras-chave: Subsidiária integral, Empresa pública, Convênio de compartilhamento de estruturas

\begin{abstract}
El presente trabajo tiene como objetivo estudiar acerca de la subsidiaria de propiedad total, tal como se define en el artículo 251 de la Ley de Sociedades. En particular, se presentará a sus características, así como sus órganos de administración . Después se abordará en el establecimiento de propiedad total de las companhias públicas como una forma de descentralizar sus operaciones en el mercado. ¿Cuál es el instrumento legal para ser ejecutado entre la compañía pública y su subsidiaria en compartir estructuras? En conclusión, se constató que el instrumento utilizado es un Acuerdo (artículo 116, § 1 Ley 8.666/93).
\end{abstract}

Keywords: Subsidiaria de propiedad total, Compañía pública, Acuerdo en las estructuras de intercambio

\footnotetext{
${ }^{1}$ Doutorando em Direito pelo Centro Universitário de Brasília, UniCEUB, Brasília - DF, (Brasil). Advogado da Empresa Brasileira de Correios e Telégrafos, ECT, Brasília, DF, (Brasil.)
} 


\section{INTRODUÇÃO}

A constituição de uma sociedade anônima unipessoal permanente foi uma inovação advinda com a Lei 6.404, de 1976 - Lei das Sociedades por Ações (LSA). Em seu artigo 251 estabeleceu-se que "a companhia pode ser constituída, mediante escritura pública, tendo como único acionista sociedade brasileira".

A ausência de maiores definições na LSA tem levado a doutrina a divergir sobre as características desta companhia, bem como os órgãos societários indispensáveis à constituição e ao funcionamento dela. Divergem, ainda, acerca de quais dispositivos da LSA são aplicáveis à subsidiária integral.

Conquanto a divergência que será apresentada, fato é que, nos dias atuais, tem-se verificado que até mesmo o Estado tem feito uso da instituição de subsidiária integral, como, por exemplo, com a criação de subsidiária integral de empresas públicas - caso analisado no presente trabalho - e de sociedade de economia mista. A razão pelo uso atual da subsidiária integral reveste-se no intuito de o Estado ter uma maior participação nas atividades econômicas.

Assim, no presente artigo, pretende-se, inicialmente, abordar sobre a constituição de sociedade anônima unipessoal. Após, passa-se a exposição das características desta sociedade, bem como sobre os órgãos obrigatórios e facultativos compreendidos em sua estrutura.

O outro assunto abordado é a possibilidade de a empresa pública constituir subsidiária integral. Trata-se da interpretação dada pelo Supremo Tribunal Federal ao artigo 37, XX, da $\mathrm{CF} / 88$, conforme se examinará no presente trabalho.

Uma vez instituída a subsidiária integral de empresa pública, levanta-se o questionamento acerca de qual instrumento adequado a ser utilizado para se estabelecer o compartilhamento de estruturas e/ou recursos entre as referidas empresas.

A fim de analisar as características da subsidiária integral, os seus órgãos estatutários, bem como responder ao questionamento proposto, mister a revisão bibliográfica com base em renomados doutrinadores de Direito Empresarial.

Além disso, acerca do questionamento, levar-se-á em consideração casos práticos verificados, a exemplo da relação jurídica entre a Caixa Econômica Federal e sua subsidiária integral - a Caixa Participações SA; e os Correios e sua subsidiária integral - a Correios Participações SA.

Pretende-se, assim, por este artigo, apresentar uma proposta de um instrumento jurídico adequado a ser utilizado pela empresa pública e sua subsidiária integral quando do 
compartilhamento de suas estruturas e/ou recursos para o desenvolvimento de suas atividades cotidianas.

\section{POSSIBILIDADE DE CONSTITUIÇÃO DE SOCIEDADE ANÔNIMA UNIPESSOAL}

A possibilidade de constituição de sociedade anônima unipessoal adveio com a Lei 6.404, de 1976 - Lei das Sociedades por Ações. Antes disso, na vigência do Decreto-lei 2.627, de 1940, havia a previsão apenas da sociedade unipessoal provisória (CARVALHOSA, 2014, p. 156). Nesse caso, uma vez tornando-se unipessoal, a sociedade entraria em liquidação caso não restaurasse o mínimo de sete acionistas até a assembleia geral ordinária seguinte. Daí o porquê dizer que a unipessoalidade da sociedade era provisória.

Lembra Carvalhosa que a ideia da constituição de uma Sociedade Anônima - SA unipessoal permanente era, inclusive, repelida por doutrinadores da época, a exemplo de Valverde (1959, p. 245) que ao comentar a possibilidade de se constituir uma SA unipessoal assim criticava:

\footnotetext{
Com absoluta falta de senso, sugeriu-se a possibilidade de se constituir sociedade anônima com um único subscritor ou acionista. Gente que ouve cantar o galo, mas não sabe onde. Nenhuma lei consagra, ou poderá consagrar, essa monstruosidade jurídica - indivíduo-sociedade. Nem mesmo a Lei alemã de 1937, a mais revolucionária de todas (...) ousou admitir essa anomalia. (...) Aqui, porém, sob o calor dos trópicos, tudo se funde, até o bom senso.
}

Outro crítico da sociedade anônima unipessoal era Cañizares (apud PEIXOTO, 1972, p. 248), segundo o qual, "se é sociedade não pode ser unipessoal, e se é unipessoal, não pode ser sociedade".

Fato é que, conquanto as críticas, com o advento da Lei 6.404, de 1976, instituiu-se duas figuras da SA unipessoal: a sociedade unipessoal provisória - com previsão no artigo 206, "d"; e a sociedade unipessoal permanente, denominada de subsidiária integral e com fundamento nos artigos 251 a 253 da LSA. Esta é o foco do presente artigo.

\section{SOCIEDADE UNIPESSOAL PERMANENTE: A SUBSIDIÁRIA INTEGRAL}

Atentando-se para a exposição de motivos do Projeto da Lei 6.404, não se extrai, com 
precisão, a finalidade da inserção desta espécie societária no referido diploma. Assim constou na exposição de motivos:

A companhia que tem por único acionista outra sociedade brasileira é expressamente admitida e regulada no art. 252 (251 da lei), que dá juridicidade ao fato diário, a que se veem constrangidas as companhias, de usar "homens de palha" para subscreverem algumas ações, em cumprimento ao requisito formal de número mínimo de acionistas. Mas o Projeto não admite a companhia brasileira subsidiária integral de companhia estrangeira, para deixar claro que a lei veda a subordinação do interesse da sociedade nacional ao da estrangeira.

Carvalhosa (2014, p. 158) critica essa fundamentação expondo que além de ser pouco esclarecedora, utiliza-se "de uma linguagem político-nacionalista não condizente com o espírito do diploma". Na verdade, de acordo com o autor, a razão da inserção deste tipo societário não decorreu do falso quadro societário - tal qual afirmado na exposição de motivos -, mas sim "na suplantação, a partir dos anos 30, da visão da companhia como contrato, para erigi-lo como instituto" (CARVALHOSA, 2014, p. 158), complementando:

\begin{abstract}
Nessa esteira, os doutrinadores voltam-se para o fenômeno econômico da empresa, dando-lhe cidadania jurídica. Surge uma visão contemporânea da sociedade mercantil como forma de personificação da empresa. A empresa personifica-se por meio da sociedade comercial. Abandona-se a remota origem econômica da sociedade mercantil, que era a reunião de capitais diversos. Admite-se que essa forma de acumulação de capitais, que justifica a sociedade pluripessoal, pode deixar de existir, na medida em que uma única pessoa ostente todo o capital necessário à formação e operação de uma empresa mercantil. A pluralidade de sócios é, pois, fruto do superado contratualismo como expressão da reunião de capitais. Já o acionista único é fruto do institucionalismo, que se funda na empresa e não mais no contrato (CARVALHOSA, 2014, p. 158-159).
\end{abstract}

Verifica-se, por esta citação, que a ideia de pluralidade de sócios era fruto do superado requisito contratual da sociedade, que é totalmente dispensável nas sociedades institucionais, a exemplo da subsidiária integral.

Nos termos do artigo 251 da LSA, a subsidiária integral constitui uma sociedade unipessoal, cujo único acionista é uma sociedade brasileira. Disso decorre, tal qual constante na exposição de motivos ao Projeto de Lei, que as sociedades estrangeiras, conquanto autorizadas a funcionar no país, não poderão constituir uma subsidiária integral (EIZIRIK, 2011, p. 387).

Para o desenvolvimento do tema proposto, indispensável traças algumas características da subsidiária integral:

a) O controle que a sociedade controladora deterá sobre ela é total de modo que emitirá todas as ações da controlada. Não há se falar, assim, em “existência de 
outros acionistas, ainda que com participação ínfima no capital”, uma vez que haveria descaracterização do instituto (EIZIRIK, 2011, p. 387).

b) A subsidiária integral deve ser obrigatoriamente uma SA, haja vista que do conceito extrai-se a expressão “companhia" (EIZIRIK, 2011, p. 389).

c) O único acionista da subsidiária integral não pode ser uma pessoa natural. Deve, assim, o seu único acionista ser uma pessoa jurídica - uma sociedade -, o que não significa dizer que essa sociedade tenha de ser, necessariamente, uma SA, "dada a expressão genérica 'sociedade' utilizada” pela LSA (EIZIRIK, 2011, p. 389). No mesmo sentido pondera Carvalhosa (2014, p. 163):

Pergunta-se, outrossim, se a sociedade controladora poderá ser de outro tipo que não anônima. A norma, ao falar, genericamente, em "sociedade brasileira", não faz qualquer exceção ao tipo societário da controladora da subsidiária integral, contanto que esta última revista a forma anônima, tendo em vista o regime de publicidade e existência de órgãos que garantam a sua autonomia patrimonial.

Percebe-se, assim, que, por exemplo, uma sociedade limitada poderá constituir uma subsidiária integral, já que a LSA não limita a constituição de subsidiária integral por outros tipos societários. Tanto é assim, que, conforme será exposto a seguir, uma empresa pública pode constituir uma subsidiária integral, desde que haja autorização para tanto.

d) A subsidiária integral pode ser constituída de dois modos: originário ou derivado. Será originário, nos termos do artigo 251 LSA, quando a sociedade destacar parcela de seu patrimônio para a constituição da subsidiária integral. "Nesse caso, prevalecerá o procedimento de escritura pública previsto na constituição por subscrição particular” (CARVALHOSA, 2014, p. 162).

Por outro lado, será derivado, nos termos do artigo 252 LSA, quando a sociedade adquire todas as ações de outra companhia. Registra-se, no entanto, que "em ambas as hipóteses, deve ser formalizada a constituição da subsidiária integral, sob pena de ser essa unipessoalidade configurada como provisória" (CARVALHOSA, 2014, p. 162).

e) A subsidiária integral possui nome empresarial próprio o qual não se pode confundir com o de sua controladora.

f) As demonstrações financeiras da subsidiária são levantadas a cada exercício, "devendo compor o balanço consolidado da controladora, mediante equivalência 
patrimonial (arts. 247 a 250 e Instrução CVM n. 247, de 1996)” (CARVALHOSA, 2014, p. 168).

Atinente às funções da subsidiária integral, lembra Carvalhosa (2014, p. 165), que ela pode ser constituída com o intuito de: ser uma sociedade de propósito único, criada para emissão de valores mobiliários; ser uma sociedade permissionária ou concessionária de serviços públicos.

Além disso, com a instituição de uma subsidiária integral permite-se a formação de "profit centers e de projetos no grupo societário. Assim, pode-se transformar uma divisão de fábrica em uma subsidiária integral, a fim de atribuir-lhe estratégia de margens e de resultados próprios" (CARVALHOSA, 2014, p. 165). Em suma, no caso exemplificado, a subsidiária integral é criada no intuito de descentralizar as atividades de sua instituidora a fim de desenvolver projetos específicos dentro de um grupo societário que serão melhor desenvolvidos por intermédio de uma outra companhia.

No que tange à estrutura da subsidiária integral, lembra Eizirik (2011, p. 391) que "é obrigatória, em princípio, a existência de órgãos de administração na subsidiária integral". Trata-se, na verdade, de uma norma de ordem pública consubstanciada no princípio da indelegabilidade das funções e competências. Desse modo, como não se previu excepcionalidade na LSA, deve, em regra, a subsidiária possuir todos os órgãos sociais.

Ressalta-se, no entanto, que há divergência doutrinária acerca de quais órgãos sociais são obrigatórios numa subsidiária integral. Eizirik (2011, p. 391) comenta que a realização de assembleia geral, por exemplo, é totalmente dispensável, mormente considerando o próprio significado da palavra assembleia, segundo o qual traduz-se na reunião de "duas ou mais pessoas para discutir e deliberar sobre assuntos de interesse comum". Deveria assim, de acordo com este doutrinador, ter sido previsto na LSA que a assembleia geral é dispensável, tal qual ocorre nas sociedades limitadas, conforme previsão no artigo 1.072, $\S 1^{\circ}$ do Código Civil. Assim complementa Eizirik (2011, p. 392):

\footnotetext{
A exigência da assembleia geral em sociedade unipessoal seria contrária a um dos princípios básicos do direito societário, que é o de dispensar o cumprimento de formalidades inúteis, em atenção à natureza das atividades que regula e que demandam uma disciplina mais informal do que aquela existente no âmbito do direito público.
}

Eizirik (2011, p. 392) ainda propõe que a assembleia geral poderia ser validamente 
substituída por uma escritura declaratória assinada pelo único acionista. Esta escritura teria os mesmos efeitos de uma assembleia geral ordinária ou extraordinária.

Carvalhosa (2014, p. 169), por outro lado, entende que o legislador, ao omitir quanto às regras aplicáveis à subsidiária integral, acabou por reforçar o entendimento segundo o qual "aplicam-se quase que literalmente os institutos organizacionais internos da companhia fechada”. Desse modo, segundo Carvalhosa (2014, p. 169), impensável uma companhia, ainda que possua um único sócio, que não seja organizada observando-se o princípio da indelegabilidade de funções dos órgãos da companhia.

Sendo assim, no entender deste doutrinador, "não poderá o estatuto da subsidiária suprimir a assembleia geral, outorgando à diretoria, além das funções de representação, também as de deliberação" (CARVALHOSA, 2014, p. 169-170). Tampouco se admitiria, no direito societário brasileiro, que a atribuição dos poderes deliberativos da subsidiária integral ficasse a cargo da assembleia geral da controladora.

Conquanto a divergência, na prática, bem como no estudo que se fará no tópico seguinte, tem-se se verificado que os estatutos das subsidiárias integrais contemplam a assembleia geral, mormente levando-se em consideração o já citado princípio da indelegabilidade de funções dos órgãos da companhia, o qual está insculpido no artigo 139 LSA, a saber: "as atribuições e poderes conferidos por lei aos órgãos de administração não podem ser outorgados a outro órgão, criado por lei ou pelo estatuto".

Eizirik afirma que, caso no estatuto se preveja - por apego ao formalismo - a previsão de assembleia geral, “ela será totalitária, por definição, já que estará presente o único acionista”. Desse modo, haverá dispensa dos procedimentos convocatórios, quorum de instalação, de deliberação e de composição de mesa para direção dos trabalhos, exigências estas previstas na LSA aplicáveis as companhias.

Concernente aos órgãos de direção (conselho de administração e diretoria), Carvalhosa (2014, p. 167-168) entende que a subsidiária integral não poderá ter conselho de administração, uma vez que somente se lhe aplica os órgãos sociais previsto na LSA para as sociedades fechadas, a saber: assembleia geral, diretoria e conselho fiscal. Nestes termos expõe o doutrinador:

A subsidiária integral é reconhecida pela lei societária como uma sociedade fechada que assume obrigações em seu próprio nome e exerce direitos como pessoa jurídica autônoma. Por outro lado, está impedida a subsidiária de possuir Conselho de Administração, na medida em que seus membros deverão ser, necessariamente, acionistas (art. 146). Consequentemente, os administradores não serão acionistas, 
mesmo porque não pode pessoa jurídica - no caso a controladora - exercer tal função (art. 146). Terá a subsidiária, como referido, todos os órgãos sociais previsto na lei para sociedades fechadas, como sejam a assembleia geral, a diretoria e o conselho fiscal, de funcionamento não permanente.

Entende, assim, Carvalhosa (2014, p. 169), que à assembleia geral da subsidiária integral caberá, por exemplo, “aprovar as demonstrações financeiras e o relatório da diretoria, nomear os diretores e, se for o caso, os membros do Conselho Fiscal".

Por outro lado, Eizirik (2011, p. 393) entende que a subsidiária integral conterá um conselho de administração caso seja de capital autorizado ou companhia aberta. E complementa: "no caso, não será necessário atender ao disposto no artigo 146, nos termos do qual os membros do conselho de administração devem ser acionistas" (EIZIRIK, 2011, p. 393).

Conquanto a divergência, no caso do presente estudo, está se diante de uma subsidiária integral constituída por uma empresa pública. Nestes casos, é imprescindível que a subsidiária possua um conselho de administração - CA, mormente considerando o disposto no Decreto 757, de 19 de fevereiro de 1993. Trata-se de decreto que dispõe sobre a composição das diretorias e dos conselhos de administração, fiscal e curador nas empresas públicas, nas sociedades de economia mista, nas suas subsidiárias e controladas, bem assim em quaisquer empresas sob o controle direto ou indireto da União.

De acordo com este Decreto, será de seis membros o número máximo no CA destas pessoas jurídicas, dentre os quais, um deles, será indicado pelo Ministro do MPOG - Ministério do Planejamento, Orçamento e Gestão. A necessidade da instituição do CA, ainda que se trate de uma subsidiária integral, decorre do poder fiscalizatório que o MPOG, por intermédio do Departamento de Coordenação e Governança das Empresas Estatais - DEST, exerce sobre as empresas estatais (PLANEJAMENTO, 2016).

No que se refere à diretoria, não há dúvidas - tampouco divergência doutrinária -que ela é indispensável ainda que se trate de uma sociedade unipessoal. Aos membros da diretoria aplicam-se os mesmos deveres atribuídos aos diretores de companhias anônimas pluripessoais (EIZIRIK, 2011, p. 393).

No tocante aos diretores, Eizirik (2011, p. 393) pondera que eles "devem praticar seus atos com autonomia, não se submetendo aos interesses eventualmente conflitantes entre a controladora e a sua subsidiária integral, uma vez que pode haver interesses conflitantes de credores, de trabalhadores e da comunidade que devem ser respeitado". Trata-se, assim, da necessidade de separação dos atos praticados pela controladora e a subsidiária integral. 
Por fim, acerca do conselho fiscal também se verifica divergência doutrinária. Bulgarelli (1988, p. 127 e s.), por um lado, entende que o funcionamento deste órgão reside na dialética maioria-minoria dos sócios. Sendo assim, tendo em vista que na subsidiária integral está se diante de um único sócio, dispensável a instituição do conselho fiscal.

Por outro lado, Carvalhosa (2014, p. 168), entende ser necessária a instalação do conselho fiscal uma vez que a função deste órgão reside em "fiscalizar a gestão financeira dos administradores e dar parecer sobre suas contas e respectivas demonstrações financeiras. Por essa razão, "é absolutamente compatível o seu funcionamento[conselho fiscal] na subsidiária integral. Além disso, lembra Carvalhosa (2014, p. 168), que o funcionamento do conselho fiscal é de interesse da própria controladora, uma vez que "a conduta dos administradores da subsidiária será alcançada por essa fiscalização".

No mesmo sentido, Calixto Salomão (apud EIZIRIK, 2011, p. 393) entende ser imprescindível a instalação do conselho fiscal, tendo em vista a tutela dos interesses de terceiros.

Eizirik (2011, p. 393), por sua vez, entende que é facultativa a instalação do conselho fiscal a depender dos interesses do acionista controlador que pode, "se julgar conveniente, manter o órgão em atividade, para aferir a legitimidade e regularidade da atuação dos diretores".

No caso de subsidiária integral de empresa pública, a instalação de conselho fiscal é obrigatória nos termos do citado Decreto 757, de 1993. Ressalta-se que um dos conselheiros e respectivo suplente, inclusive, será indicado pelo Ministro da Fazenda, como representante do Tesouro Nacional. Isso decorre da necessidade de a União fiscalizar as sociedades nas quais tem controle direto ou indireto.

O modo de funcionamento do conselho fiscal na subsidiária integral, no entender de Carvalhosa, pode ser não permanente - apenas nos exercícios sociais em que for instalado a pedido do acionista controlador -, tal qual se depreende da dicção do artigo 161 da LSA.

No caso dos conselhos fiscais de subsidiária integral de empresa pública, pela pesquisa realizada, tem-se que o modo de funcionamento é permanente, a exemplo do que se verifica no caso da CaixaPar - Caixa Participações SA (artigo 22 de seu Estatuto Social) e da CorreiosPar - Correios Participações SA (artigo 24 de seu Estatuto Social).

Além destes órgãos, sugere Eizirik (2011, p. 393), que nada impede a subsidiária integral de criar outros órgãos estatutários, "de natureza consultiva e que assessorem a diretoria, como comitês de auditoria, de política ambiental, de recursos humanos, etc”. 
Um último ponto a ser tratado acerca desta sociedade unipessoal é a possibilidade ou não de ela constituir uma subsidiária integral. Ter-se-ia, assim, a subsidiária da subsidiária.

Carvalhosa (2014, p. 172) entende isso não ser plausível, na medida em que a figura do controlador implica a existência de uma pluralidade de sócios. Assim comenta:

\begin{abstract}
Ora, a subsidiária investidora no capital de outra subsidiária não seria controladora, mas única acionista. Faltariam, assim, os destinatários do regime de publicidade, que são, inclusive, os acionistas minoritários da controladora. Haveria, por sua vez, um distanciamento do pass trough entre os minoritários da controladora e os da subsidiária da subsidiária, ficando difícil o controle da legalidade e legitimidade dos atos dos seus administradores.
\end{abstract}

Desse modo, conclui Carvalhosa (2014, p. 172), “uma sociedade pluripessoal poderá ter várias subsidiárias. Não poderá a controladora, no entanto, criar subsidiária da subsidiária".

Por outro lado, Eizirik (2011, p. 394) não vê qualquer impedimento legal à existência de subsidiária de subsidiária exemplificando, inclusive, que "caso a companhia A incorpore as ações de B para transformá-la em subsidiária integral e B seja a única acionista de C, (...) não há qualquer razão jurídica a impedir tal operação, que resultará na situação de subsidiária de subsidiária".

Em razão de não haver vedação legal, conclui-se que é possível a criação de subsidiária integral de subsidiária integral. Houvesse alguma ilegalidade, certamente o legislador teria efetuado a proibição na própria LSA ao tratar da sociedade unipessoal. Em não fazendo esta ressalva, entende-se permissivo, mormente considerando a máxima de que no direito privado o que não é defeso está permitido. Ressalta-se que da análise atinente sobre este tópico - criação de subsidiária integral de subsidiária integral - pode advir o questionamento sobre a possibilidade de constituição de subsidiária integral de subsidiária integral de empresa pública, o que não é respondido nesta breve análise necessitando de maiores estudos.

\title{
3. SUBSIDIÁRIA INTEGRAL DE EMPRESA PÚBLICA
}

No texto Constitucional de 1988 constou a possibilidade de empresa pública constituir subsidiária desde que haja autorização legislativa para tanto, conforme se depreende do artigo 37, XX: "depende de autorização legislativa, em cada caso, a criação de subsidiárias das entidades mencionadas no inciso anterior, assim como a participação de qualquer delas em empresa privada".

Registra-se que o Supremo Tribunal Federal, na ADI 1649/DF, ao interpretar o artigo 
37, XX, CF/88, entendeu ser prescindível a autorização específica para a instituição de cada uma das subsidiárias de uma mesma entidade. Considerou, assim, que "a autorização legislativa para a criação de subsidiárias de empresa pública, sociedade de economia mista, autarquia ou fundação pública, a que se refere o inciso XX do art. 37 da CF, possui caráter genérico”.

Desse modo, a título exemplificativo, o Banco Nacional do Desenvolvimento BNDES teve a autorização legislativa concedida pela Lei 5.662, de 1971; a Caixa Econômica Federal - CEF teve a autorização pela Lei 11.908, de 2009; a Empresa Brasileira de Correios e Telégrafos - Correios pela Lei 12.490, de 2011.

Ressalta-se que, no caso dos Correios, a possibilidade de constituição de subsidiária integral advém desde o Estatuto Social da empresa de 1979 - já revogado - o qual fora aprovadopelo Decreto 83.726, de 1979. O texto constitucional atual, no entanto, exige que a instituição de subsidiária integral de empresa pública se dê mediante autorização legislativa e não meramente constar no Estatuto Social da empresa. Assim, no caso dos Correios, adequouse ao normativo constitucional com o advento da Lei 12.490, de 2011 que decorreu da conversão da Medida Provisória 532, de 2011.

\subsection{INSTRUMENTO JURÍDICO ADEQUADO PARA SE ESTABELECER RELAÇÃO JURÍDICA ENTRE A SUBSIDIÁRIA INTEGRAL E A EMPRESA PÚBLICA QUE A CONSTITUIU}

Exposta essa explicação inicial, advém o seguinte questionamento. Uma vez instituída a subsidiária integral da empresa pública, qual a forma utilizada para se estabelecer uma relação jurídica entre elas?

Este questionamento advém do fato de que para a subsidiária integral poder desenvolver de forma regular suas atividades ela necessitará de apoio - ainda que mínimo - da empresa pública que a constituiu. Assim, no primeiro momento, a título exemplificativo, ela não terá um quadro próprio de pessoal - até porque o seu quadro de pessoal terá, inicialmente, de ser aprovado pelo DEST e, posteriormente, ser contratado mediante concurso público de provas ou de provas e títulos, a teor do artigo 37, II, da CF/88.

Necessitará, assim, a subsidiária integral da empresa pública de auxílio - estrutura, recursos materiais e humano - para o desempenho de atividades das mais elementares até as mais complexas. Desse modo, questiona-se, por qual meio se externalizará, reitera-se, a relação jurídica entre elas? 
Esse questionamento decorre do próprio artigo 245 da LSA, uma vez que os administradores não podem, em prejuízo da companhia, favorecer uma sociedade controlada.

Assim, caso haja operações entre as sociedades, deve-se observar que elas sejam estritamente comutativas ou com pagamento compensatório adequado, sob pena de os administradores responderem perante a companhia pelas perdas e danos resultantes de atos praticados com infração ao referido dispositivo.

Nesse sentido, Eizirik (2011, p. 357) pondera que "o caráter comutativo das relações entre controladora e controlada assegura uma espécie de 'via dupla', de modo que a sociedade controladora não favoreça nem prejudique a controlada".

A fim de que essa comutatividade - entendida como equivalência de obrigações convencionadas entre as partes - se perfaça entre a empresa pública e a subsidiária integral, mister o estabelecimento de um instrumento no qual se assegure a ideia de equilíbrio entre prestação e contraprestação entre elas.

Não se constata, no entanto - quer na doutrina, quer na jurisprudência - a previsão de um instrumento adequado para se estabelecer esta relação jurídica. Na prática tem-se verificado a celebração de um Convênio, nos moldes da Lei 8.666, de 1993, entre a empresa pública e a subsidiária integral. Foi assim no caso da Caixa com a CaixaPar (DOU, 2009, p. 50) e no caso dos Correios com a CorreiosPar (DOU, 2015, p. 113).

Conquanto apresente características sui generis, a celebração de um Convênio, nos termos da Lei de Licitações e Contratos Administrativos, mostra-se como um documento jurídico plausível considerando os interesses recíprocos e comuns entre os partícipes - empresa pública e sua subsidiária integral. Diz-se recíproco tendo em vista que a subsidiária foi constituída, nos casos exemplificados, no intuito de dar fiel cumprimento ao objeto social de sua controladora. É o que verifica, por exemplo, no caso da CorreiosPar, cujo objeto social encontra-se delimitado nos seguintes termos:

\footnotetext{
Art. $4^{\circ}$ A CORREIOSPAR tem por objeto social: I - constituir subsidiárias, adquirir controles ou participações acionárias em sociedades empresárias, bem como proceder às alienações correspondentes, com vistas ao cumprimento de atividades dispostas no objeto social da ECT (...). (grifos)
}

De igual modo, se verifica essa o intuito de cumprimento ao objeto social de sua controladora no caso da CaixaPar, tal qual se extrai do artigo $6^{\circ}$ de seu Estatuto Social: 
comprimento de atividade dispostas no objeto social da CEF (...). (grifos)

Ainda considerando os casos da Caixa e dos Correios, tem-se, pelo Convênio, que a empresa pública e sua subsidiária compartilharão estrutura e recursos - humanos e materiais necessários à execução de suas atividades. Consequentemente, nos termos do citado artigo 235 LSA, haverá, a posteriori, o reembolso das despesas provenientes do compartilhamento de atividades entre elas.

Nesse contexto, cabe destacar que o Tribunal de Contas da União (TCU, 2006) entendeu ser juridicamente possível a celebração de convênios entre órgãos e/ou entidades públicos desde que o objeto do convênio esteja necessariamente contemplado nos objetivos institucionais de cada convenente e represente o atingimento de um ou mais objetivos comuns a ambos, verbis:

DENÚNCIA. PARCIALMENTE PROCEDENTE. DETERMINAÇÃO. CIÊNCIA AO DENUNCIANTE E A ÓRGÃOS INTERESSADOS. ARQUIVAMENTO. É juridicamente possível a celebração de convênios entre órgãos e/ou entidades públicos, inclusive de esferas diferentes de governo, desde que no objeto do convênio os dispêndios financeiros, assim como os recursos humanos e materiais, sejam utilizados exclusivamente para a consecução do objeto conveniado e, sendo pelo menos um dos convenentes entidade/órgão federal, que seja observada a legislação federal incidente sobre a matéria.

[VOTO]

(...)

6. Em atendimento a meu despacho, o Ministério Público trouxe à colação excerto do Voto condutor do Acórdão 522/2006 - Plenário que trata de tema análogo ao ora examinado, a saber, convênios firmados por diversos órgãos públicos federais com a Polícia Militar e com o Corpo de Bombeiros Militar do Distrito Federal.

7. Na mencionada deliberação, este Tribunal entendeu, como mencionou a Unidade Técnica, "ser juridicamente possível a celebração de convênios entre órgãos e/ou entidades públicos, inclusive de esferas diferentes de governo, desde que o objeto do convênio esteja necessariamente contemplado nos objetivos institucionais de cada convenente e represente o atingimento de um ou mais objetivos comuns a ambos; os dispêndios financeiros, assim como os recursos humanos e materiais, sejam utilizados exclusivamente para a consecução do objeto conveniado e, sendo pelo menos um dos convenentes entidade/órgão federal, que seja observada a legislação federal incidente sobre a matéria".

Constata-se, assim, por este julgado do TCU ser juridicamente possível a celebração de convênios entre órgãos públicos, desde que no objeto do convênio os dispêndios financeiros, bem como os recursos humanos e materiais, sejam utilizados exclusivamente para a consecução do objeto conveniado. 
Ainda no que concerne ao referido instrumento jurídico, extrai-se do artigo $116, \S 1^{\circ}$ da Lei 8.666, de 1993, que a celebração de convênio, acordo ou ajuste pelos órgãos ou entidades da Administração Pública dependerá de prévia aprovação de competente plano de trabalho.

A proposição de referido plano de trabalho se dará pela organização interessada e conterá, nos termos do citado artigo, no mínimo, as seguintes informações: identificação do objeto a ser executado; metas a serem atingidas; etapas ou fases de execução; plano de aplicação dos recursos financeiros; cronograma de desembolso; previsão de início e fim da execução do objeto, bem assim da conclusão das etapas ou fases programadas; se o ajuste compreender obra ou serviço de engenharia, comprovação de que os recursos próprios para complementar a execução do objeto estão devidamente assegurados, salvo se o custo total do empreendimento recair sobre a entidade ou órgão descentralizador.

Ocorre que, no momento da celebração dos referidos Convênios, nos casos exemplificados (Caixa e CaixaPar; Correios e CorreiosPar), as empresas públicas não dispuseram de elementos objetivos que permitissem definir de imediato um plano de trabalho, mormente considerando não se saber, ao certo, quais estruturas e recursos seriam compartilhados.

Em vista disso, previu-se nos referidos Convênios a celebração de Termos Aditivos Operacionais - TAOs a serem celebrados, a posteriori, entre a empresa pública e a subsidiária integral. Nestes TAOs é que estarão previstos os respectivos planos de trabalho em cumprimento ao disposto no artigo 116, $\S 1^{\circ}$ da Lei 8.666, de 1993.

Assim, por exemplo, enquanto a subsidiária integral não contar com pessoal próprio que realize suas atividades contábeis, poderá ela - por intermédio da celebração de um TAO com a área contábil de sua controladora - valer-se da estrutura da empresa pública, ressarcindolhe, posteriormente, os custos dispendidos com as atividades desenvolvidas. Neste TAO, reitera-se, é que constará o plano de trabalho das atividades a serem desenvolvidas, em observância ao referido dispositivo legal.

A ideia, assim, é manter na controlada (subsidiária integral) uma estrutura pequena, própria de uma sociedade que tem por objeto o cumprimento das atividades previstas no objeto social de sua controladora.

Esse foi, inclusive, o entendimento da equipe técnica da $2^{\text {a }}$ Secex do TCU no relatório de acompanhamento da TC 028.935/2008-4:

$(\ldots)$ 
3.4.5 Pode-se perceber que a estrutura da CAIXAPAR é bastante simplificada. Isso se deve ao fato de que muitas atividades da empresa, como auditoria interna, controladoria, administração de recursos humanos, assessoria jurídica, ouvidoria e gestão de riscos, serão desenvolvidas pelas unidades equivalentes da CAIXA.

3.4.6 Para viabilizar essa estrutura de suporte, verificou-se que foi firmado um Convênio de Compartilhamento entre a CAIXA e a CAIXAPAR. Além disso, para definir as condições específicas do apoio a ser prestado pelas unidades da CAIXA, estão sendo firmados aditivos ao referido Convênio de Compartilhamento, a exemplo do assinado em 12/11/2009 com a Auditoria Interna (fls. 141/143, anexo 4).

3.4.7 Da análise dos dados e informações disponibilizados, pode-se concluir que a estrutura da CAIXAPAR é adequada para o desenvolvimento de suas atividades. A estrutura enxuta facilita o fluxo de informações e torna a implementação das decisões mais ágil. (grifos)

(...)

Ressalta-se que a terminologia "contrato" não se mostra adequada, uma vez que não se está diante de uma prestação de serviço propriamente dita, mas sim de uma coexistência de interesses mútuos que é típico dos convênios.

Ora, se a subsidiária integral foi constituída para desenvolver o objeto social da empresa pública e, por outro lado, a empresa pública possui interesse que a sua subsidiária execute atividades que lhe torne mais competitiva no mercado, mister reconhecer o interesse recíproco entre elas. Em se tratado de interesse recíproco, surge, como solução jurídica, a celebração de um convênio, nos moldes da Lei 8.666, de 1993, e não de contratos que, por outro lado, regulam tipicamente interesses contrapostos.

\section{CONSIDERAÇÕES FINAIS}

Em síntese, por este estudo, verificou-se que a sociedade anônima unipessoal é uma espécie societária tipificada na LSA e plenamente utilizada na prática. Caracterizada, pelo fato de ter um único sócio - que pode ser uma sociedade anônima ou não -, a subsidiária integral conta com uma estrutura apartada da sociedade que a constituiu.

$\mathrm{Na}$ verdade, como se verificou, a exigência de separação das operações da controladora e da controlada - subsidiária integral - decorre do próprio artigo 245 da LSA, que estabelece norma de conduta aos administradores das referidas companhias.

As características da subsidiária integral levam à noção de que uma sociedade opta por sua constituição como forma de descentralizar as suas atividades, concedendo mais agilidade e melhor participação no mercado. 
Tanto é assim que, atualmente, tem-se verificado a criação por parte de empresas do Estado - empresas públicas e sociedades de economia mista - de suas subsidiárias integrais. Até mesmo empresas públicas que são essencialmente prestadoras de serviço público - a exemplo dos Correios - têm optado na constituição de subsidiária integral como forma de a subsidiária dar cumprimento às atividades dispostas no objeto social de sua controladora.

Em vista disso, levantou-se o questionamento acerca de qual seria o instrumento apropriado para regular a relação jurídica entre a empresa pública e a subsidiária integral. A doutrina e/ou a jurisprudência não trazem um instrumento apropriado.

Atentando-se para o fato de que ambas - empresa pública e sua subsidiária - pertencem, direta ou indiretamente, ao Estado, mister observância aos ditames da Lei 8.666, de 1993. Sendo assim, amolda-se à espécie a celebração de um Convênio de execução de atividades operacionais comuns e complementares e de compartilhamento de estruturas e recursos materiais/humanos.

Trata-se, conforme defendido neste artigo, de um instrumento sui generis, mas que uma vez atendido os requisitos da Lei 8.666 , de 1993 , em especial o disposto no artigo $116, \S 1^{\circ}$ e a observância ao citado artigo 245 LSA, é juridicamente possível de serem celebrados entre as empresas para fins de compartilhamento de estruturas.

Ressalta-se, por fim, que a Controladoria-Geral da União - CGU fez auditoria no Convênio de compartilhamento de estruturas celebrado entre a CEF e a sua subsidiária integral, a CaixaPar (CGU, Processo 00190.013780/2013-91, 2013). Conquanto houvesse questionamento acerca de alguns dispositivos do Convênio, o órgão de controle não questionou a espécie normativa utilizada o que leva a crer que, no âmbito da CGU, a celebração de um Convênio dessa natureza é considerada como possível, desde que, reitera-se, atendida as exigências da Lei de Licitações e Contratos Administrativos, em especial a previsão, em cada Termo Aditivo Operacional, de um plano de trabalho.

\section{REFERÊNCIAS}

BRASIL. Decreto-lei 2.627, de 1940.

Lei 5.662, de 1971.

Lei 6.404, de 1976.

. Constituição da República Federativa do Brasil, de 1988. 
. Lei 8.666, de 1993.

. Lei 11.908, de 2009.

. Medida Provisória 532, de 2011.

. Lei 12.490, de 2011.

BULGARELLI, Waldirio. O conselho fiscal nas companhias brasileiras. Revista dos Tribunais, 1988, p. 127 e s.

CARVALHOSA, Modesto. Comentários à lei de sociedades anônimas. v. 4, tomo II, 5ed.

São Paulo: Saraiva, 2014.

CONTROLADORIA GERAL DA UNIÃO. Relatório de auditoria anual de contas. Processo 00190.013780/2013-91. Relatório 201306005. Brasília/DF, 2013. Disponível em https://www.google.com.br/url?sa=t\&rct=j\&q=\&esrc=s\&source=web\&cd=1\&cad=rja\&uact= 8\&ved=0ahUKEwibk6Wci8nMAhVEQSYKHZY1BusQFggdMAA\&url=http\%3A\%2F\%2F www.caixa.gov.br\%2FDownloads\%2Fcaixa-par\%2FRelatorio-de-Auditoria-Anual-deContas_2012.pdf\&usg=AFQjCNGJL-iEz811hsg3T_6VLzqFGDCgSA. Acessado em 30 de mar. de 2016.

DIÁRIO OFICIAL DA UNIÃO. N. 91, sexta-feira, 15 de maio de 2009, Seção 1, p. 50. N. 126, segunda-feira, 6 de julho de 2015, Seção 3, p. 113.

EIZIRIK, Nelson. A lei das S/A comentada. v. III, São Paulo: Quartier Latin, 2011.

MINISTÉRIO DO PLANEJAMENTO, ORÇAMENTO E GESTÃO, Disponível em: http://www.planejamento.gov.br/assuntos/empresas-estatais/coordenacao. Acesso em 30 de mar. de 2016.

PEIXOTO, Cunha. Sociedade por ações. v. 4, São Paulo: Saraiva, 1972. VALVERDE, Miranda. Sociedades por ações. v. 1, Rio de Janeiro: Forense, 1959. TRIBUNAL DE CONTAS DA UNIÃO. Acórdão 522/2006 - Plenário. . Acórdão 3251/2010 - Plenário. 